\title{
Retrograde spread of hydrocortisone containing foam given intrarectally in ulcerative colitis
}

\author{
M J G FARTHING, M D RUTLAND, M L CLARK
}

British Medical fournal, 1979, 2, 822-824

\section{Summary and conclusions}

A method is described of estimating retrograde spread through the colon of a $10 \%$ hydrocortisone acetate foam by labelling the foam with technetium-99m sulphur colloid and observing spread after intrarectal administration by serial gamma-camera pictures. The recommended $5 \mathrm{ml}$ dose of foam reached the midsigmoid colon in all of the nine patients who had active ulcerative colitis. Furthermore, in seven the foam reached the proximal sigmoid colon.' Foam spread less extensively in five patients with quiescent disease than in those with active disease. Increasing the volume of enema to $50 \mathrm{ml}$ did not improve retrograde spread through the colon.

These results suggest that $10 \%$ hydrocortisone foam may be useful in treating patients with distal ulcerative colitis that is not necessarily limited to the rectum.

\section{Introduction}

Topical corticosteroids given as retention enemas are established treatment for distal ulcerative colitis. Aqueous solutions of hydrocortisone hemisuccinate, ${ }^{1-3}$ prednisolone-21-phosphate, ${ }^{4}$ and betamethasone-17-valerate ${ }^{5}$ effectively induce remissions, and retrograde spread through the colon has been shown radiologically. ${ }^{\circ}$ Corticosteroids given by enema relieve symptoms more rapidly than the same dose given by mouth in mild and moderately severe distal ulcerative colitis.?

Foam containing $10 \%$ hydrocortisone acetate (Colifoam) is a satisfactory alternative treatment for distal ulcerative colitis ${ }^{8}$ and is probably more acceptable to patients, ${ }^{\circ}$ although it has not been compared with other topical corticosteroid preparations in a controlled clinical trial. No evidence exists for retrograde spread of the foam through the colon; it is therefore usually given to patients in whom the upper limit of disease can be seen through the sigmoidoscope.

We have described a method of studying retrograde spread of the foam through the colon ${ }^{10}$ and now report our findings for $5 \mathrm{ml}$ and $50 \mathrm{ml}$ enemas of the $10 \%$ hydrocortisone foam.

\section{Patients and methods}

We investigated 14 patients with ulcerative colitis, nine of whom had recently relapsed and had active mucosal inflammation confirmed by sigmoidoscopy and rectal biopsy. Four had total ulcerative colitis, four disease extending to the distal descending colon, and one disease limited to the rectum. Five patients were in remission: they had no evidence of active mucosal inflammation at sigmoidoscopy (table).

Department of Gastroenterology, St Bartholomew's Hospital, London EC1A 7BE

M J G FARTHING, MB, MRCP, honorary lecturer

$M$ L CLARK, MD, FRCP, consultant physician

Department of Nuclear Medicine, St Bartholomew's Hospital, London EC1A 7BE

M D RUTLAND, MB, MRCP, research fellow
We mixed thoroughly $0.5 \mathrm{mCi}$ of technetium-99m sulphur colloid with $5 \mathrm{ml}$ of the $10 \%$ hydrocortisone acetate foam (Colifoam) in the applicator supplied by the manufacturer. We showed that mixing was adequate by taking a gamma-camera picture of the applicator containing the labelled foam before it was put into the rectum. Preliminary in-vitro studies confirmed that adding the technetium$99 \mathrm{~m}$ sulphur colloid did not alter the integrity of the foam and that the mixture remained stable for 24 hours at $37^{\circ} \mathrm{C}$.

The labelled foam was delivered into the rectum, and retrograde

Clinical and radiological features of all patients in study

\begin{tabular}{|c|c|c|c|c|c|}
\hline Case No & Sex & $\begin{array}{c}\text { Age } \\
\text { (years) }\end{array}$ & $\begin{array}{l}\text { Duration of } \\
\text { history } \\
\text { (years) }\end{array}$ & $\begin{array}{l}\text { Extent of } \\
\text { disease }\end{array}$ & $\begin{array}{l}\text { Distal extent of } \\
\text { faecal residue }\end{array}$ \\
\hline $\begin{array}{l}1 \\
2 \\
3 \\
4 \\
5 \\
6 \\
7 \\
8 \\
9\end{array}$ & $\begin{array}{l}\mathbf{M} \\
\mathbf{M} \\
\mathbf{F} \\
\mathbf{M} \\
\mathbf{M} \\
\mathbf{M} \\
\mathbf{F} \\
\mathbf{F} \\
\mathbf{M}\end{array}$ & $\begin{array}{l}31 \\
25 \\
55 \\
20 \\
40 \\
25 \\
58 \\
56 \\
39\end{array}$ & $\begin{array}{l}\text { Active disease } \\
11.0 \\
8.0 \\
26.0 \\
0.5 \\
22.0 \\
2.5 \\
6.0 \\
1.0 \\
1.0\end{array}$ & $\begin{array}{l}\text { Sigmoid } \\
\text { Sigmoid } \\
\text { Sigmoid } \\
\text { Rectum } \\
\text { Sigmoid } \\
\text { Total } \\
\text { Total } \\
\text { Total } \\
\text { Total }\end{array}$ & $\begin{array}{l}\text { Rectum } \\
\text { Distal DC } \\
\text { Distal DC } \\
\text { Distal DC } \\
\text { Proximal DC } \\
\text { Proximal TC } \\
\text { Proximal TC } \\
\text { Proximal TC } \\
\text { Proximal DC }\end{array}$ \\
\hline $\begin{array}{l}10 \\
11 \\
12 \\
13 \\
14\end{array}$ & $\begin{array}{l}\mathbf{M} \\
\mathbf{F} \\
\mathbf{M} \\
\mathbf{M} \\
\mathbf{F}\end{array}$ & $\begin{array}{l}70 \\
67 \\
28 \\
35 \\
42 \\
\end{array}$ & $\begin{array}{l}\text { In remission } \\
0.5 \\
14.0 \\
9.0 \\
14.0 \\
10.0\end{array}$ & 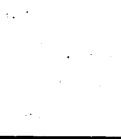 & $\begin{array}{l}\text { Proximal DC } \\
\text { Rectum } \\
\text { Rectum } \\
\text { Proximal DC }\end{array}$ \\
\hline
\end{tabular}

DC $=$ Déscending colon. TC $=$ Transverse colon .

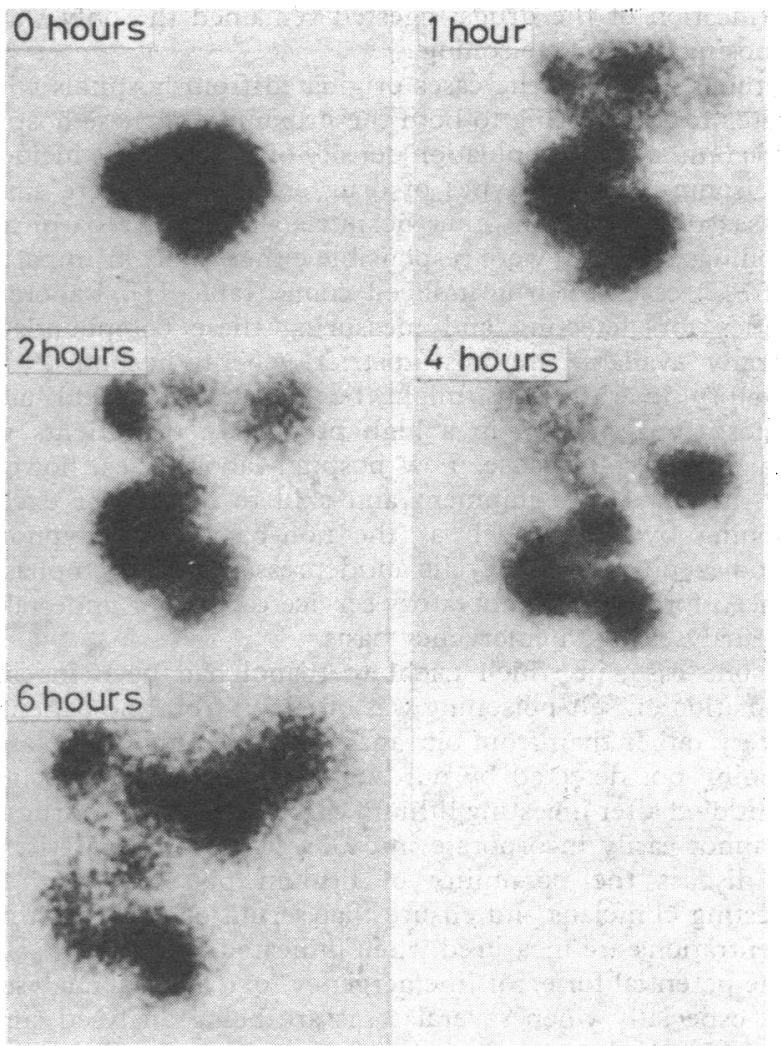

FIG 1-Posterior gamma-camera pictures taken at $0,1,2,4$, and 6 hours after $5 \mathrm{ml}$ of labelled foam was put into rectum. In this patient with active ulcerative colitis the foam reached the proximal sigmoid colon: 


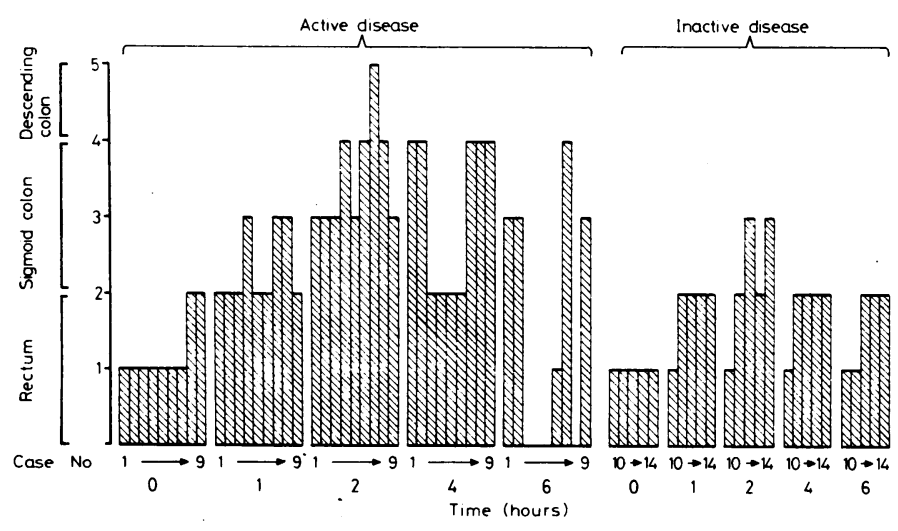

FIG 2-Results of retrograde spread through colon of $5 \mathrm{ml}$ of labelled $10 \%$ hydrocortisone foam given intrarectally to patients with ulcerative colitis.
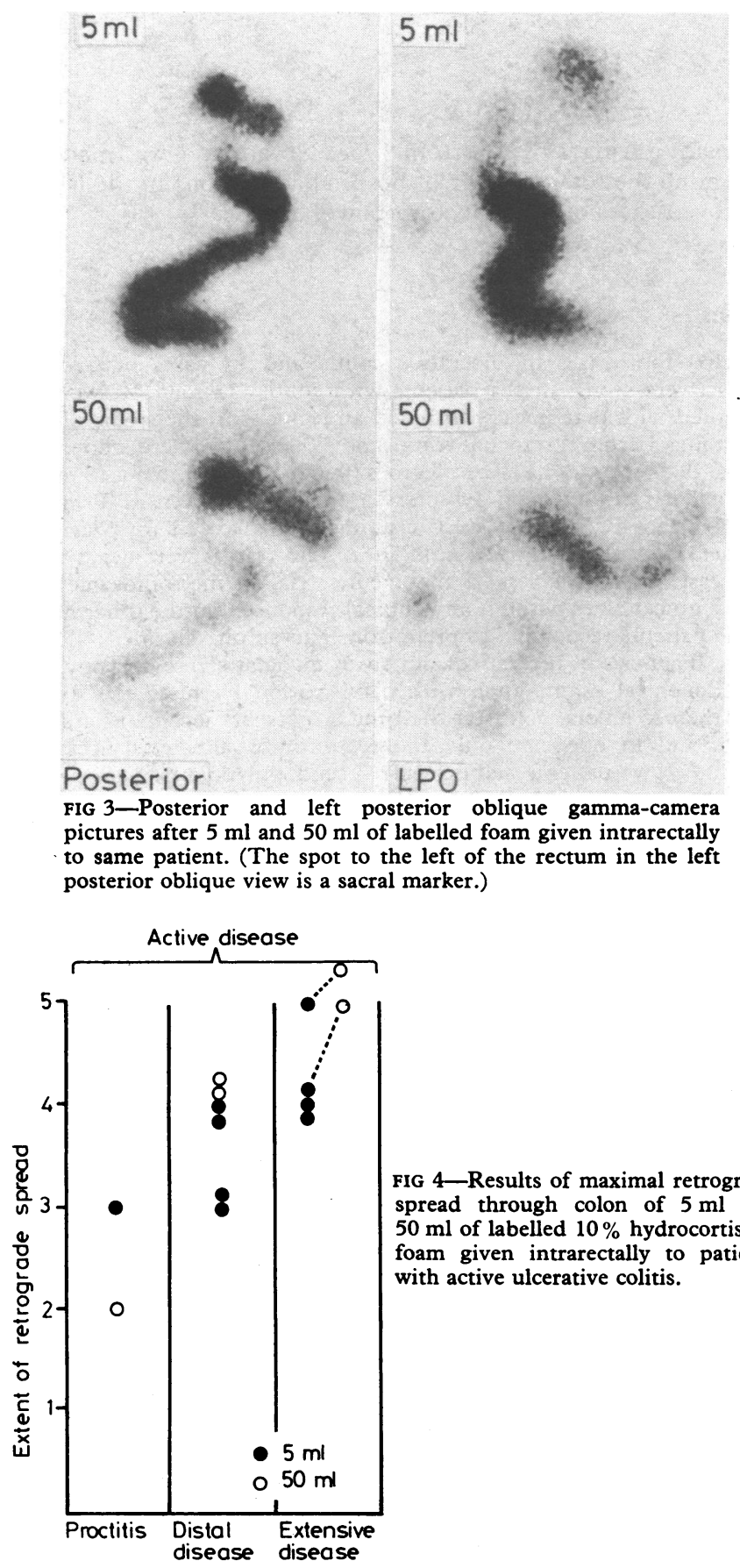

spread through the colon was followed by posterior and left posterior oblique gamma-camera pictures at $0,1,2,4$, and 6 hours (fig 1). These pictures were compared with the configuration of the colon seen on a recent barium-enema examination, and retrograde spread was scored as follows: 5 when the foam spread to the descending colon, 4 to the proximal sigmoid colon, 3 to the mid-sigmoid colon, 2 to the distal sigmoid colon, and 1 if the foam remained in the rectum. A plain abdominal radiograph was taken initially to determine the distribution of faecal residue within the colon, as we thought that this might limit retrograde spread through the colon.

In five patients with active disease, two of whom were included in the first part of this study, we measured retrograde spread of $50 \mathrm{ml}$ of labelled foam using the technique described for the $5 \mathrm{ml}$ enema. Two of these patients had extensive disease, two disease extending to the distal descending colon, and one disease confined to the rectum. The radiation spread was calculated and approved by the Isotopes Advisory Panel and the local ethical committee.

\section{Results}

In all patients, except one who was in remission, the labelled $10 \%$ hydrocortisone foam spread from the rectum into the sigmoid colon. Retrograde spread of the foam was greater in the nine patients with active disease (fig 2). Spread to the mid-sigmoid colon was observed in all of these patients, and in seven the foam reached the proximal sigmoid colon. In one the foam spread into the descending colon. Maximum spread occurred between two and four hours, after which the foam seemed to move distally again. The extent of retrograde spread was not obviously related to faecal residue in the colon: in two patients with quiescent disease and one with active disease faeces were present in the rectum but foam still spread to the sigmoid colon. Retrograde spread tended to be greater in patients with more extensive disease.

Figures 3 and 4 show the results of retrograde spread of the $50 \mathrm{ml}$ foam enema. The retrograde spread was moderately increased in the two patients with extensive active disease but the results were not dramatic; this degree of retrograde spread was seen in the three other patients with distal colitis. The gamma-camera pictures of $5 \mathrm{ml}$ and $50 \mathrm{ml}$ enemas in the same patient (fig 3) emphasise the importance of the left posterior oblique view in determining the extent of spread through the sigmoid colon, as spread would have been underestimated if examined in the posterior view alone.

\section{Discussion}

Labelling the foam appears to be a satisfactory way of estimating its retrograde spread through the colon. This study shows that $5 \mathrm{ml}$ of the $10 \%$ hydrocortisone acetate foam will in all patients with active ulcerative colitis reach the midsigmoid colon. Furthermore, in seven of nine the foam reached the proximal sigmoid colon. Less impressive retrograde spread of the same $10 \%$ hydrocortisone foam in ulcerative colitis has been reported using a similar technique."1 The extent of spread observed in that study in eight normal subjects and eight patients was similar to that seen in our patients with inactive ulcerative colitis. Radiological studies of retrograde spread of aqueous corticosteroid enemas ${ }^{612}$ have shown that spread is greater in patients with active ulcerative colitis than in patients with quiescent disease and normal subjects. Our study would suggest that this is true also for the foam enema, and we are not surprised that retrograde spread in normal subjects was limited. Disparity between our observations and those of Hay et al $^{11}$ may also be partly explained by the fact that they estimated retrograde spread on a linear scale, whereas we attempted to take into account the configuration of the colon and found that the left posterior oblique gamma-camera picture was essential for estimating spread in the sigmoid colon. Also, the exchange resin that was used as a carrier for the pertechnetate ion may have altered the integrity of the foam or its spreading characteristics.

Retrograde spread of aqueous corticosteroid enemas has been increased in some patients by giving an enema of larger volume. ${ }^{12}$ In our study, however, increasing the volume to $50 \mathrm{ml}$, a tenfold increase, did not substantially improve retro- 
grade spread, and we can see no advantage in using the larger volume.

We suggest that the $10 \%$ hydrocortisone foam may be useful in treating patients with distal ulcerative colitis that is not necessarily confined to the rectum.

MJGF is supported by a grant from the Wellcome Trust and MDR by the joint research board of St Bartholomew's Hospital.

\section{References}

1 Truelove, S C, British Medical fournal, 1956, 2, 1267.

2 Truelove, S C, British Medical fournal, 1958, 2, 1027.
3 Watkinson, G, British Medical fournal, 1958, 2, 1077.

4 Matts, S G F, British Medical fournal, 1961, 1, 165.

5 Multicentre trial, British Medical fournal, 1971, 3, 84.

6 Matts, S G F, and Gaskell, K H, British Medical fournal, 1961, 2, 614.

7 Truelove, S C, British Medical fournal, 1960, 1, 464.

8 Scherl, W D, and Scherl, B A, Diseases of the Colon and Rectum, 1973, 16, 149.

9 Clark, M L, Practitioner, 1977, 219, 103.

10 Farthing, M J G, Rutland, M D, and Clark, M L, Gut, 1979, 20, A453.

${ }^{11}$ Hay, D J, Sharma, H, and Irving, M H, British Medical fournal, 1979, 1, 1751 .

12 Swarbrick, E T, Loose, H, and Lennard-Jones, J E, Proceedings of the Royal Society of Medicine, 1974, 67, 753.

(Accepted 2 August 1979)

\title{
Inflammatory bowel disease in the West Indies
}

\author{
COURTENAY BARTHOLOMEW, ALAN BUTLER
}

British Medical fournal, 1979, 2, 824-825

\section{Summary and conclusions}

Inflammatory bowel disease is generally assumed to be rare among negroes and Indians. Over 10 years 34 cases of ulcerative colitis and 14 cases of Crohn's disease were seen in one medical and one surgical unit in Port-ofSpain, Trinidad. Twenty-six patients were Negroes, 18 were Indians, three were of mixed race, and one was Caucasian. In many of these patients the disease was extensive and several of those with Crohn's disease suffered severe complications.

The assumption that inflammatory bowel disease is rare among West Indians of African and Indian origin therefore seems to be wrong.

\section{Introduction}

The cause of both ulcerative colitis and Crohn's disease is still inconclusive, but several studies point to an association between these two diseases and also to a genetic and ethnic background. There has been little documentary evidence of inflammatory bowel disease in Asians and Africans and it is thought to be essentially a disease of temperate zones. ${ }^{1}$ Recently O'Donoghue and Clark $^{2}$ reported five patients with inflammatory bowel disease in West Indians of African stock living in Britain and stated that these diseases had not been reported in West Indians. Their patients were all Jamaicans, two of whom were born in the United Kingdom, and they suggested that exposure to environmental factors in the United Kingdom may have accounted for these diseases developing in West Indians there. We describe here 48 cases of inflammatory bowel disease in Trinidadians born and resident in Trinidad and Tobago and seen in one medical and one surgical unit at the General Hospital, Port-

\footnotetext{
University Department of Medicine, General Hospital, Port-ofSpain, Trinidad COURTENAY BARTHOLOMEW, MD, FRCPED, professor of medicine

University Department of Surgery, General Hospital, Port-ofSpain, Trinidad

ALAN BUTLER, MB, FRCS, senior lecturer in surgery
}

of-Spain, during 10 years from 1968. No attempt was made to determine the total number of hospital admissions in the island of proved cases of inflammatory bowel disease.

\section{Patients}

Thirty-four cases of ulcerative colitis and 14 cases of Crohn's disease were seen. All the patients with colitis (13 men, 21 women) presented with diarrhoea with blood and mucus in the stools. Their ages ranged from 11 to 66 years, and 20 patients were under the age of 29 . Twenty-one were Negroes (9 men) and 10 Indians ( 3 men). As bacillary and amoebic dysentery are sometimes seen in Trinidad and Tobago fresh stools were examined in all cases for Shigellae, Salmonellae, and Entamoeba histolytica. The results were negative in each case. None the less, a therapeutic trial of metronidazole was given in most cases without any clinical response. On the other hand, all the patients responded to prednisone and sulphasalazine.

The diagnosis of ulcerative colitis was made at sigmoidoscopy and by radiological examination with confirmation by histology. In 16 cases there was total colitis at the time of presentation, in 17 a distal colitis, and in one case only the rectum was affected (ulcerative proctitis). Two patients had extensive pseudopolypoid transformation of the mucosa, one developed cirrhosis of the liver with intrahepatic cholestasis, and another had an adenocarcinoma of the sigmoid colon as a complication of the colitis. One patient with severe total colitis died from a pulmonary embolism. There did not appear to be any socioeconomic preference, although many of the patients were above average in intelligence.

The 14 patients with Crohn's disease (9 men, 5 women) were aged 11 to 45 years, and six presented below the age of 29. Six were Negroes, seven were Indians, and one was Caucasian. Five patients presented with regional ileitis, one with a jejunocolitis, six with ileocolitis, and two with granulomatous colitis. Seven presented with or developed fistulas and two had perineal skin ulceration, which was very extensive in one case. In the Caucasian, a 40 -year-old man, a contiguous and fistulous lesion from a jejunitis produced a localised granulomatous colitis in the transverse colon. An external abdominal fistula and an adenocarcinoma of the jejunum eventually developed, from which the patient died. All the patients had normal chest radiographs and there was no evidence of tuberculosis. The diagnoses of these patients were confirmed by laparotomy and histology. Bowel resections were done on 12 patients.

\section{Discussion}

Ulcerative colitis is very rare in black Africa, and in 1960 Trowell ${ }^{3}$ wrote "there is no report in the literature of an African suffering from this disease and none has been encountered in 